\title{
Early Elevation of Thioredoxin-I Serum Levels Predicts 28-Day Mortality in Patients with Sepsis [Corrigendum]
}

Li X, Shen H, Zhou T, et al. J Inflamm Res. 2021;14:3837- $\quad$ The authors apologize for this error. 3848 .

The authors have advised due to an error at the time of assembling the Tables, Table 1 on page 3841 is incorrect.

The correct Table is as follows.

Table I Comparison of Baseline Clinical Characteristics Between Survivors and Non-Survivors

\begin{tabular}{|c|c|c|c|}
\hline & Survivors & Non-Survivors & $P$ value \\
\hline Age (years) & $65 \pm 16$ & $68 \pm 13$ & 0.172 \\
\hline Gender (male/female) & $109 / 35$ & $24 / 19$ & 0.012 \\
\hline Coronary heart disease & 45 (31.3\%) & $13(30.2 \%)$ & 0.899 \\
\hline Hypertension & $38(26.4 \%)$ & II (25.6\%) & 0.916 \\
\hline Type 2 diabetes & $15(10.4 \%)$ & 5 (11.6\%) & 0.822 \\
\hline Chronic renal failure & II (7.8\%) & $4(9.3 \%)$ & 0.725 \\
\hline COPD & $23(16.0 \%)$ & $8(18.1 \%)$ & 0.684 \\
\hline Length of ICU stay(days) & $8(3 \sim 2 I)$ & $6(2 \sim 22)$ & 0.025 \\
\hline Survival days & 28 & $10(2 \sim 22)$ & 0.000 \\
\hline Trx-I (ng/mL) & I5.2 (2.3-789.5) & $382.5(7.5-1732.5)$ & 0.000 \\
\hline $\mathrm{Lac}(\mathrm{mmol} / \mathrm{L})$ & $2.2(0.5-11.0)$ & $3.2(0.9-18)$ & 0.000 \\
\hline PCT (ng/mL) & $4.10(0.40-200.00)$ & I3.9 (0.4-200.0) & 0.000 \\
\hline CRP $(\mathrm{mg} / \mathrm{mL})$ & 99.40 (7.48-200.0) & $127.6(18.6-468.0)$ & 0.000 \\
\hline IL-6 (ng/mL) & $74.6(2.9-754.3)$ & $376.3(|3.4-9| 2.1)$ & 0.000 \\
\hline$\triangle$ SOFA & $6(2-18)$ & II (3-15) & 0.000 \\
\hline HR (beats/min) & $101 \pm 22$ & $110 \pm 33$ & 0.033 \\
\hline RR (beats/min) & $24 \pm 6$ & $24(12-40)$ & 0.048 \\
\hline MAP $(\mathrm{mmHg})$ & $84 \pm 18$ & $70 \pm 17$ & 0.000 \\
\hline Temperature & $37.5 \pm 1.0$ & $37.8 \pm 1.3$ & 0.000 \\
\hline WBCs $\left(10^{9}\right)$ & $\mid 5.1 \pm 8.0$ & $13.5 \pm 6.4$ & 0.222 \\
\hline НСТ\% & $32.7 \pm 9.1$ & $3 I . I \pm 7.0$ & 0.295 \\
\hline $\operatorname{PLT}\left(10^{9}\right)$ & $172(2 \mid .0-527.0)$ & I30.0 (I7.0-364.0) & 0.025 \\
\hline
\end{tabular}

(Continued) 
Table I (Continued).

\begin{tabular}{|l|l|l|l|}
\hline & Survivors & Non-Survivors & P value \\
\hline $\mathrm{Scr}(\mathrm{umol} / \mathrm{L})$ & $96.4(33.7-507.6)$ & $144.0(44.9-1477.9)$ & 0.002 \\
\hline $\mathrm{TBIL}(\mathrm{mmol} / \mathrm{L})$ & $17(3.1-122.0)$ & $19.6(4.6-124.7)$ & 0.029 \\
\hline $\mathrm{PaO} 2 / \mathrm{FIO} 2(\mathrm{mmHg})$ & $187.8(44.8-675.0)$ & $150.2(63.3-417.1)$ & 0.001 \\
\hline $\mathrm{GCS}$ & $12(3-15)$ & $9(3-15)$ & 0.000 \\
\hline
\end{tabular}

Abbreviations: Trx-I, thioredoxin; Lac, lactate; PCT, procalcitonin; CRP, C-reactive protein; IL-6, interleukin-6; $\triangle \mathrm{SOFA}$, sequential organ failure assessment score; HR, heart rate; RR, respiratory rate; MAP, mean artery pressure; WBC, white blood cells; PLT, platelet; HCT, hematocrit; TBIL, total bilirubin; GCS, Glasgow Coma Score.

\section{Publish your work in this journal}

The Journal of Inflammation Research is an international, peerreviewed open-access journal that welcomes laboratory and clinical findings on the molecular basis, cell biology and pharmacology of inflammation including original research, reviews, symposium reports, hypothesis formation and commentaries on: acute/chronic inflammation; mediators of inflammation; cellular processes; molecular mechanisms; pharmacology and novel anti-inflammatory drugs; clinical conditions involving inflammation. The manuscript management system is completely online and includes a very quick and fair peerreview system. Visit http://www.dovepress.com/testimonials.php to read real quotes from published authors. 